\title{
GATHERING THE VOICE OF THE STUDENTS FOR ACCREDITATION PURPOSES THROUGH THEIR DEFINITION OF "ENGINEER"
}

\author{
Sylvie Doré, Patrick Terriault, and Christian Belleau \\ Mechanical Engineering, École de technologie supérieure \\ sylvie.dore@etsmtl.ca, patrick.terriault@etsmtl.ca, and christian.belleau@etsmtl.ca
}

\begin{abstract}
This paper proposes a novel indirect assessment method to capture the voice of the students for program accreditation purposes. It consists of asking students, individually and then in teams, to draw up a list of keywords they associate with being an engineer and to write a formal definition of engineer. The raw data (list of keywords and definitions) is closed coded for the twelve graduate attributes (GAs) defined by Engineers Canada. First-year, mid-program and last-year students participated in the study in order to verify change of perception as students advance through the program. Results are compared for individual and teams, as well as for the different student populations. Sufficient insight into the program's contribution to the development of graduate attributes in its student population (or apparent lack thereof), information that can be used for continual program improvement, was gained to warrant internal validity of the method.
\end{abstract}

Keywords: accreditation, indirect assessment, student voice, definition of "Engineer", graduate attributes, change in perception.

\section{INTRODUCTION}

One of the measures used by the Canadian Engineering Accreditation Board (CEAB) during the accreditation process is an institution's capacity to demonstrate that the graduates of a program possess the twelve graduate attributes (GA) defined in the Criteria and Procedures (reproduced in Appendix A) [3]. The Board also evaluates if a proper continuous improvement process is in place. Accreditation is now based on an outcomes-based model. One of the characteristics of an effective outcomes-based assessement is that it uses multiple measures in order to maximize reliability and validity [6] It is therefore recommended that direct assessment of student performance, through exam results, oral presentations, project reports, etc., especially when rubrics specifying performance level and threshold performance are defined, be supplemented by indirect measures. It is also recommended that the voice of multiple stakeholders, including that of the students, be taken into account [1].
However, according to Pons [7], the voice of the students is under represented in published scientific literature.

Different institutions use a variety of means to indirectly capture student input. Surveys and forums or focus groups are the most often used methods. For example, surveys have been used to measure familiarity with the GAs, the relative importance of GAs and their level of dependencies [9]; to gather students' perception on the ways their program supported them in attaining the GAs and how it could be improved to better do so. $[4,5]$. Student lead forums were held at University of Manitoba to obtain input on how to improve the programs [8].

The objective of this paper is to present a novel method to capture student input regarding the GAs and to present the type of results one can expect. Through a definition of (mechanical) engineer written by students, the method is used to verify which attributes students associate with being a (mechanical) engineer at three moments in the program (upon entering, mid-way and exiting the program) thereby indirectly measuring if the program contributes to a change in perception. The underlying assumption is that students integrate key words relating to the attributes that they value in their definition of (mechanical) engineer. It employs a mixed methodology as the source of data is qualitative but the sample size is large enough to warrant statistical analysis. Although this study reports results from mechanical engineering, the method is sufficiently general that in can be applied in all fields of engineering.

In the following sections, we will present the methodology employed and results obtained. This is followed by a discussion before reaching a conclusion.

\section{METHODOLOGY}

\subsection{Case description}

When using qualitative data, it is important to describe the test case in order to verify if the method is applicable in other contexts or to determine if the results obtained are generalizable.

The study took place in the mechanical engineering program at École de technologie supérieure (ÉTS), a francophone engineering school in Montreal. ÉTS is a monofaculty institution. It was founded in 1974 to train 
technologists. It was transformed into an engineering school in 1989. Today, it is the second largest faculty in Canada in terms of number of undergraduates. In 20182019, the mechanical engineering program welcomed 344 new students and a total of 1050 student were registered in the program. Undergraduate engineering programs at ÉTS count 105 credits of courses. Students must also undertake three mandatory four month work terms. They must also successfully pass a 1 credit module on professional regulation and ethics (PEP 110 Encadrement de la profession et éthique professionnelle) before their third work term (between 72 and 102 credits). All courses are given in blocs of 3.5 hours per week (generally in a 90 minutes course +30 minutes break +90 minutes course format). Furthermore, students spend another two or three hours of practice or laboratory work per week in every course. They must supplement these five or six hours of in class/laboratory training with personal study. Class size is relatively small, mandatory courses counting between 40 to 60 students. To accommodate the large number of students registered in the program, mandatory courses are offered with multiple sections.

Students are admitted on a continuous basis (fall, winter and summer semesters). Given certain constraints, students can also leave for their work terms during the semester of their choosing. Consequently, students do not advance in their respective programs as a cohort.

ÉTS has a very diverse student population. Programs are designed for students with a technical background, i.e. having completed a collegiate technical program. In mechanical engineering, we admit students coming from 20 different such programs. In 2018-2019, students graduating from technical programs delivered in the province of Quebec composed 61,9\% of the mechanical engineering student population. This proportion was supplemented by another 6,4\% graduating from similar programs in France. In the same year, 26,9\% of admitted students were graduates of scientific collegiate programs in natural sciences or computer sciences and mathematics. However, these students must spend two semesters learning technical skills before being admitted in the regular engineering programs.

ÉTS is part of the University du Québec network whose fundamental values include accessibility to higher education. Therefore, there is no selection upon entry. As long a prospective student has a collegiate level degree in an appropriate field and has sufficient mastery of French, he or she is admitted.

The population is dominantly male. In mechanical engineering, males compose $94 \%$ of the student population and $85 \%$ of faculty.

\subsection{Data collection}

Anonymous data was collected during regular class time in three different mandatory courses.
First-year student data was collected during the 2018 fall semester in the first design course of the program (MEC129 Développement de produits assisté par ordinateur). It took place at the beginning of the first lecture, before the course outline and the graduate attributes were presented. A sheet, which included the following instructions was distributed and used for data gathering.

Individual task (front side of sheet):

Draw up a list of keywords that you would like to include in your definition (no limits to the number of words).

Write a personal definition of "mechanical engineer". You can use more than one sentence.

\section{Team task (back side of sheet)}

Taking inspiration from the lists of keywords you produced individually, draw up a list of keywords you would like to include in the team produced definition (no limits to the number of words).

Write a team definition of "mechanical engineer". You can use more than one sentence.

Students were given five (5) minutes to perform the individual task and seven (7) for the three to five member team task. Teams then handed-in their individual and collective definitions.

For first-year students, this task was part of a learning activity meant to present the program and the place of MEC129 within the program. No explanations with regard to accreditation were given to the students prior to them writing the definition.

Data from mid-program and final-year students were collected respectively in a fourth semester finite element course (MEC423 Méthode des éléments finis des corps déformables) fifteen minutes before the midcourse break and in a seventh semester mechatronics course (MEC788 Mécatronique), at the end of the lecture. In both cases, data collection took place during the fourth week of the semester. Students were told that data would be used for accreditation purposes but were not reminded of the graudate attributes. They were also told that the activity was compulsory, anonymous and was not evaluated. No student opted out.

Table 1 summarizes the number of participants for each population. The list of keywords and definition produced by one student individually or by a team of students constitutes one observation.

Table 1: Number of participants per population

\begin{tabular}{|l|c|c|}
\hline Population & Individual & Team \\
\hline First year & 135 & 37 \\
\hline Mid program & 104 & 34 \\
\hline Last year & 113 & 32 \\
\hline All & 352 & 138 \\
\hline
\end{tabular}




\subsection{Data analysis}

Raw data were analysed using a closed coding method, using the graduate attributes as codes. It was necessary to build a lexicon of synonyms for certain attributes. The lexicon is reproduced in Appendix B. Each observation was coded by two judges with $50 \%$ overlap. This required that each judge code $2 / 3$ of the observations. It is worth to mention that observations were randomly attributed to the judges. Results from the two judges were compared for each observation. When a difference was noted, the judges discussed and reconciled their results.

When coding the keywords, the definition was often consulted to uncover the intended meaning. For example, the word "responsible" can take on two meanings: one of accountability (one accepts the consequences of his or her decisions or actions), which would be coded as GA8 (professionalism), and the other of being in charge of (one is responsible of a task) which would be coded as GA11 (project management) depending on context. When in doubt, the word was not coded which results in conservative code counts.

The word "leadership" was never coded because we could never determine if it meant assuming leadership within a team of peers (GA6) or taking charge of a group of subordinates (GA11).

We formed three data sets: keywords only (W), definitions only (D) and a combination of keywords or definitions. It is important to note that if a code appeared more than once in a given observation, it was counted only once.

From these three data sets, we extracted two types of measures:

- GA count is the number of GAs coded in a given observation resulting in discrete interval data;

- Population proportion is the number of observations for a given code divided by the population size. Population proportion was determined for each of the twelve GAs. This constitutes nominal data with a binomial distribution because the code can only take two values (present or absent) for a given observation.

\section{RESULTS}

\subsection{Comparison of data sets}

We observed different patterns in the raw data.

- Certain students (or teams) drew up a list of keywords and wrote a definition around those keywords. Two situations arose:

○ for certain observations, exactly same words appear in both the list of keywords and in the definition;

- for other observations, particularly those with a very long list of keywords, or for those produced by students who appeared to have difficulty with written communication (presence of numerous spelling and grammatical errors, defective semantics), the definition counted a smaller number of GA than the list of keywords.

- Certain students only drew up a list of keywords without writing a definition.

- Other students only wrote a definition without drawing up a list of keywords.

We were faced with the question of which data set to use: only the keywords (W), only the definitions (D) or a combination of keywords or definition (W or D; if a GA appears in the keywords or definition, it is counted once; if it appears in both, again, it is counted only once).

Figure 1 illustrates a box and whisker plot of GA counts for all observations, The three distributions average $3.03 \pm 1.51,2.72 \pm 1,34$ et $3.80 \pm 1,51$ GAs respectively (Medians are respectively 3, 3 and 4). The data sets were compared using a Mann-Whitney test with a level of significance of $\alpha=0,05$. The null hypothesis that the average counts were equal could not be rejected for $\mathrm{W}$ dataset when compared to $\mathrm{D}$ (i.e. keywords count the same number of GAs than definitions). The test did reveal that that the keywords or definitions data set (W or D), counted more GAs than either the keyword only (W) or definition only (D) data set.

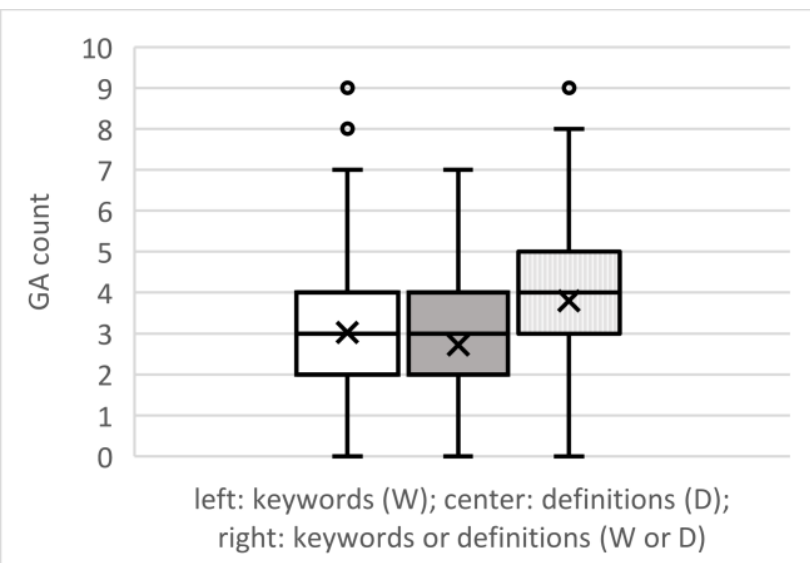

Figure 1. Comparison of standardised distribution of GA counts in keywords (W), definitions (D) and keywords or definitions $(\mathrm{W}$ or $\mathrm{D})$

Because the keywords or definition (W or D) data set was richer and better captured student intent, we used only this data set for all further analyses.

\subsection{Comparison of individuals and teams}

Table 2 summarises the GA counts for different populations and whether data was produced on an individual basis or in teams as well as the conclusion of the statistical tests. 
Once again a Mann-Whitney test with a level of significance of $\alpha=0.05$ was used to determine if the differences were significant. Except for the first year students, teams included significantly more graduate attributes in the list of keywords or definitions than individuals.

When going through the exercise as a team, we would expect students to take inspiration from their individual reflections, share them and start afresh with a combined list of keywords and new definition which would result in teams having higher GA counts. However some teams adopted what appeared to them to be the best result produced by the individuals in the team, thereby replicating an individual result.

Table 2: Comparison of counts for individuals and teams

\begin{tabular}{|l|c|c|c|c|c|c|c|}
\hline \multirow{2}{*}{ Population } & \multicolumn{2}{|c|}{$\begin{array}{c}\text { Average } \\
\text { count }\end{array}$} & \multicolumn{2}{c|}{$\begin{array}{c}\text { Standard } \\
\text { deviation }\end{array}$} & \multicolumn{2}{|c|}{ Median } & \multirow{2}{*}{ Conclusion } \\
\cline { 2 - 8 } & T & I & T & I & T & Concll \\
\hline First year & 3,8 & 4,8 & 2,29 & 2,64 & 4 & 5 & $T>1$ \\
\hline Middle & 3,9 & 5,1 & 2,11 & 2,83 & 4 & 4 & $T=1$ \\
\hline Last year & 4 & 5,4 & 2,67 & 1,93 & 4 & 5,5 & $T>1$ \\
\hline
\end{tabular}

Because some programs might not have a sufficiently large number of students to conduct statistical tests on team data, we will continue to present results for individuals and teams.

\subsection{Comparison of student populations}

\subsubsection{Graduate attribute counts}

Table 2 also allows us to compare the three student populations (first-year students, those in the middle of the program and last-year students). At first glance, data seems to show that the GA count increases with seniority, whether the data is produced individually or in teams. However, the box and whisker plots, reproduced in Figures 2 and 3 cast a doubt on this first impression.

Results of Mann-Whitney tests $(\alpha=0.05)$ are reported in Table 3.

For individual data, there is no significant difference between the first-year students and those at mid-program, nor between mid-program and last-year students. However, the difference is significant between first-year and last-year students.

For team data, mid-program and last-year students identified more GAs than first-year students did. There is no significant change between mid-program and last-year students.

There is therefore a significant increase in identified GAs with seniority but it does not appear at the same point in the program depending if one uses individual or team data.

Table 3: Results of statistical tests comparing populations

\begin{tabular}{|l|c|c|c|c|c|c|}
\hline \multirow{2}{*}{ Population } & \multicolumn{3}{|c|}{ Individual } & \multicolumn{3}{c|}{ Teams } \\
\cline { 2 - 7 } & $\begin{array}{l}\text { First } \\
\text { year }\end{array}$ & Mid & $\begin{array}{c}\text { Last } \\
\text { year }\end{array}$ & $\begin{array}{c}\text { First } \\
\text { year }\end{array}$ & Mid & $\begin{array}{c}\text { Last } \\
\text { year }\end{array}$ \\
\hline First year & N/A & $=$ & $<$ & N/A & $<$ & $<$ \\
\hline Mid & $=$ & N/A & $=$ & $>$ & N/A & $=$ \\
\hline Last year & $>$ & $=$ & N/A & $>$ & $=$ & N/A \\
\hline
\end{tabular}

\subsubsection{Graduate attributes identified}

The proportion of the population having included a given GA in the keywords or definition was computed for all twelve GAs. Results all shown in Fig. 4 for data produced by individuals and in Fig. 5 for teams.

Table 4 contains the numerical values of those proportions which were used to rank the graduate attributes in decreasing order (rank 1 is given to the graduate attribute that was included in greatest proportion for a given population while rank 1 indicates the smallest proportion).

A two-tailed proportion test (level of significance $=$ 0.05 ) was performed on each graduate attribute to see if there was a significant change between the populations.

For data produced by individuals, the graduate attributes exhibiting a significant difference are (GA in parentheses indicate a lowering of rank):

- First-year compared to mid-program : GA2 and GA9

- Mid-program to last-year: (GA2), (GA4), GA8, GA9, GA10 and GA12

- First-year compared to last-year : GA8, GA9, GA10 and (GA11)

For data produced by teams, the graduate attributes exhibiting a significant difference are

- First-year compared to mid-program : GA1,GA GA2, GA4, (GA7), GA9, GA10 and (GA12)

- First-year compared to mid-program : (GA1) and GA10

- Mid-program to last-year GA2, GA4, (GA7), GA8, GA9 and GA10

Some graduate attributes demonstrate trends. For example, design (GA4) is the top ranking graduate attribute for all populations, whether individuals or teams produced the data. On the other hand, life- long learning (GA12), is almost systematically last, or at least in the bottom tier, in all cases. For other attributes, such as knowledge base (GA1), the ranking varies greatly depending on the population and if individuals or teams produced the data. 

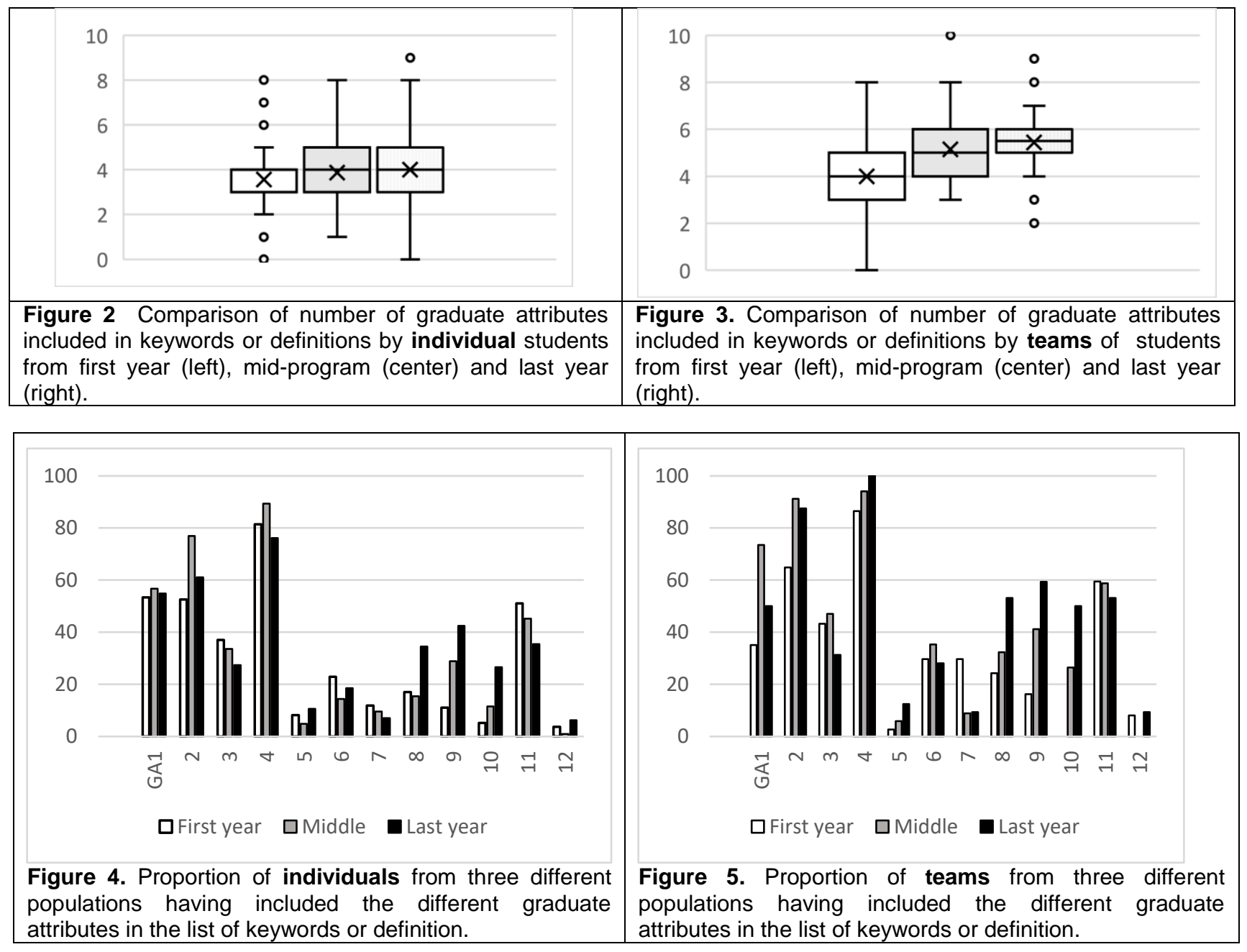

Table 4: Ranking of graduate attributes with respect to proportion of population (\%) having included the graduate attribute in the list of keywords or definition

\begin{tabular}{|c|c|c|c|c|c|c|c|c|c|c|c|c|}
\hline \multirow[b]{3}{*}{ Rank } & \multicolumn{6}{|c|}{ Individual } & \multicolumn{6}{|c|}{ Team } \\
\hline & \multicolumn{2}{|c|}{ First year } & \multicolumn{2}{|c|}{ Mid-program } & \multicolumn{2}{|c|}{ Last year } & \multicolumn{2}{|c|}{ First year } & \multicolumn{2}{|c|}{ Mid-program } & \multicolumn{2}{|c|}{ Last year } \\
\hline & GA & $\%$ & GA & $\%$ & GA & $\%$ & GA & $\%$ & GA & $\%$ & GA & $\%$ \\
\hline 1 & GA4 & 81,48 & GA4 & 89,42 & GA4 & 76,11 & GA4 & 86,49 & GA4 & 94,12 & GA4 & 100,00 \\
\hline 2 & GA1 & 53,33 & GA2 & 76,92 & GA2 & 61,06 & GA2 & 64,86 & GA2 & 91,18 & GA2 & 87,50 \\
\hline 3 & GA2 & 52,59 & GA1 & 56,73 & GA1 & 54,87 & GA11 & 59,46 & GA1 & 73,53 & GA9 & 59,38 \\
\hline 4 & GA11 & 51,11 & GA11 & 45,19 & GA9 & 42,48 & GA3 & 43,24 & GA11 & 58,82 & GA8 & 53,13 \\
\hline 5 & GA3 & 37,04 & GA3 & 33,65 & GA11 & 35,40 & GA1 & 35,14 & GA3 & 47,06 & GA11 & 53,13 \\
\hline 6 & GA6 & 22,96 & GA9 & 28,85 & GA8 & 34,51 & GA6 & 29,73 & GA9 & 41,18 & GA1 & 50,00 \\
\hline 7 & GA8 & 17,04 & GA8 & 15,38 & GA3 & 27,43 & GA7 & 29,73 & GA6 & 35,29 & GA10 & 50,00 \\
\hline 8 & GA7 & 11,85 & GA6 & 14,42 & GA10 & 26,55 & GA8 & 24,32 & GA8 & 32,35 & GA3 & 31,25 \\
\hline 9 & GA9 & 11,11 & GA10 & 11,54 & GA6 & 18,58 & GA9 & 16,22 & GA10 & 26,47 & GA6 & 28,13 \\
\hline 10 & GA5 & 8,15 & GA7 & 9,62 & GA5 & 10,62 & GA12 & 8,11 & GA7 & 8,82 & GA5 & 12,50 \\
\hline 11 & GA10 & 5,19 & GA5 & 4,81 & GA7 & 7,08 & GA5 & 2,70 & GA5 & 5,88 & GA7 & 9,38 \\
\hline 12 & GA12 & 3,70 & GA12 & 0,96 & GA12 & 6,19 & GA10 & 0,00 & GA12 & 0,00 & GA12 & 9,38 \\
\hline
\end{tabular}




\section{DISCUSSION}

\subsection{Of results obtained}

Results show that all twelve GAs were identified.

They also show that first year students have a good sense of what an engineer does (GA1, 2, 3, 4 and 11). As they grow in seniority, they have a better sense of what an engineer "is" by having identified more professional attributes (GA8, 9 and 10). What appears to be lacking is an identification of the conditions under which engineers practice (GA5 and 6). In a sense, it offers a rare glimpse into how their identity shifts as they advance through the program.

The results reflect the program: the vast majority of courses concentrate on technical issues (GA1, 2, 3, 4, 5). Though there has been some improvements over the years, professional attributes (GA6 through GA12) are not well integrated in technical courses. Taught in separate courses by non-engineers, it is possibly sending the message that these attributes are not valued by engineers.

The following paragraphs highlight particular graduate attributes:

- Design (GA4): is the top ranking GA. Students captured is (arguably) considered the most important feature that distinguishes engineers from other professionals and from scientists (although some students did define engineers as a scientist who solves problems).

- Communication (GA7) diminishes with seniority. In the mechanical engineering program, the communications course is co-taught with the first design course of the program (MEC129) in which the first-year students were sampled for this study. Communications skills are only marginally evaluated thereafter. It is possible that first-year students, who are about to live this experience, are influenced by this situation but that the effect wears out with time.

- Use of engineering tools (GA5) ranks in the low tier despite the fact that use of tools is extensively taught and evaluated throughout the program. The vast majority of engineering tools used in the program are software (computer aided design, finite element analysis, symbolic calculator, Maltab and Simulink, etc.) Perhaps, for this generation of students, the use of electronic tools is so common, both in their professional and everyday life, that it is considered a given and not worth mentioning.

- Teamwork (GA6) is also ranked low despite that some instruction on the subject is given at the beginning of the program and is used extensively thereafter. Like GA 5, perhaps it is considered a given and not worth mentioning. Another possible explanation is that teamwork is pervasive in all spheres of activities. When defining "engineer", students possibly concentrated on what distinguishes engineers from other professionals, thereby excluding teamwork, instead of explicitly citing the conditions under which engineering tasks are executed.

- Life-long learning (GA12) has the lowest rank. At ETS, this GA follows the province's professional association (Ordre des ingénieurs du Québec $O I Q$ ) model: assess what one has learned, determine what one lacks, and develop a plan to reduce the gap. It is evaluated at two points in the program, in the first-year and capstone design courses. Students have ample occasions to practice life-long learning skills when filling out their professional portfolios, a mandatory activity related to their work terms. Because these activities are not labelled as life-long learning but are associated with professionalism, students might not explicitly express this GA. Another possible explanation is that life-long learning is required of all professionals, not only engineering. Like for teamwork, students possibly concentrated on what distinguishes engineers from other professionals.

\subsection{Of the method}

The method presents many strengths and advantages:

- It is easy to implement.

- It does not require much time from participants. The activity holds in about 20 minutes including giving instructions. (We could even question if students were given enough time.)

- It produces very large participation rates if done in class.

- It can be carried out individually or in teams. Team observations require less coding but sample size can be small for some programs. Furthermore it does not necessarily reflect real impact because team data can reflect the result of one or few individuals in the team, which creates a bias. However it can lead to very constructive discussions between students.

- It does not require any particular infrastructure if carried out with paper and pen.

- Once coded, data can be easily analysed with simple tools.

- Debriefing, which was done for first-year students, leads to very constructive discussions between students and instructor.

- It offers an opportunity to introduce (or reintroduce) students to the GAs. 
It suffers the following weaknesses.

- Coding, if done manually, is tedious and requires double coding with interjudge reconcialiation for more robust data. However, using a software qualitative analysis tool, such as NVivo, would require an extensive lexicon and careful review of coding results.

- It is difficult to compare the results of this study with that of other studies because of differences in study design and the particularities of the student population at ÉTS. One can argue that when defining a concept, a person would include what he or she judges essential and important in the definition. The closest studies conducted in Canadian universities along those lines are that of Seniuk Cicek [9] and Sullivan and Brennan [10]. Seniuk Cicek surveyed students (and other stakeholders) for their familiarity with the GAs, their perception of the relative importance of GAs for Engineer-in-Training (EIT) at the beginning of his/her career and GA level of dependencies. Sullivan and Brennan explored how GAs are assessed across Canadian Engineering programs and raise the question of GA importance.

We offer two recommendations. Firstly, to conduct the sampling during class. In our view, the inconvenience of cutting back about 20 minutes of class time far outweighs the inconvenience of soliciting volunteers outside the classroom and the possible biases this can create. Secondly, we recommend adjusting the lexicon of synonyms (Appendix B) depending on the context. For example, a systems engineering program would probably consider adding the words "integration, integrate, integrator" to GA4 Design.

\section{CONCLUSION}

This paper presented a novel indirect method of gathering data for accreditation purposes capturing the students voice. It consists of asking students, at three moments in the program, to write a list of keyword they associate with (mechanical) engineer, and then write a definition. The data is then coded for the presence of the graduate attributes as defined by Engineers Canada.

The method gathers important information on the program's contribution to the development of graduate attributes in its student population (or apparent lack thereof) and also provides information that can be used for continual program improvement, thus demonstrating internal validity. Demonstration of external validity, which would lead to generalisation, warrants further investigation by conducting similar studies in other programs at ÉTS and in other engineering schools or faculties. It would also be interesting to use the method with other stakeholders, faculty and sessional instructors to start with, as well as practicing engineers. Furthermore, a more in depth qualitative study is necessary to validate the explanations we put forward to explain certain results.

\section{Acknowledgements}

The authors wish to thank Brigitte Castonguay for providing information on the program and student population.

\section{References}

[1] Trudy W. Blanta and Charles Blaich, "Closing the assessment loop", Change: The Magazine of Higher Learning, vol. 43, no. 1, pp. 22-27, 2011.

[2] M. Drapeau, "Les critères de scientificité en recherche qualitative", Pratiques psychologiques, vol. 10, pp. 79-86, 2004.

Available as of April 26, 2019, from, https://www.sciencedirect.com/science/article/pii/S1 $\underline{269176304000057}$

[3] Engineers Canada. Canadian Engineering Accreditation Board: 2018 Accreditation Criteria and Procedures. Revised November 2018. Criteria and Procedures \{ ISSN 1708-8054\}

Available as of April 26, 2019 from: https://engineerscanada.ca/sites/default/files/accredit ation/Accreditation-criteria-procedures-2018.pdf

[4] Brian Frank and Sue Fostaty Young, "What can our students do: year 2 of graduate attribute assessment at Queen's University," Proc. CEEA Canadian Engineering Education Conf., CEEC11, Andy Fisher (ed.) (St. John's, NL; 6-8 June 2011), 6 pp., 2011.

Available as of April 26, 2019 from https://ojs.library.queensu.ca/index.php/PCEEA/arti cle/view/3587

[5] Andrew J. B. Milne, Roydon Fraser, and Natalie Chow, "First-year versus fourth-ear and online versus paper-andpencil responses to a graduate attribute self-assessment tool and exit survey", Proc. CEEA Canadian Engineering Education Conf., Andy Fisher (ed.) (Halifax, NB; 19-22 June 2016), 8 pp., 2016

Available as of April 26, 2019 from https://ojs.library.queensu.ca/index.php/PCEEA/arti cle/view/6516

[6] Deborah Nusche, Assessment of learning outcomes in higher education: a comparative review of selected practices. OECD Education working paper no. 15. OECD (ed.), Paris, 49 pp., 2008.

Available as of April 26, 2019 from https://doi.org/10.1787/244257272573

[7] Dirk Pons, "Relative Importance of Professional Practice and Engineering Management Competencies." European Journal of Engineering Education vol. 41, no. 5, pp. $530-$ 547, 2016

Available as of April 26, 2019 from https://doi.org/10.1080/03043797.2015.1095164 
[8] Dario Schor, Kathryn Marcynuk, Matthew Sebastian, Witold Kinsner, Ken Ferens, Cyrus Shafai, and Nariman Sepehri. "Curriculum enhancement and evaluation of graduate attributes and outcomes through student-run forums," Proc. CEEA Canadian Engineering Education Conf., CEEC11, Andy Fisher (ed.) (St. John's, NL; 68June 2011), 6 pp., 2011.

[9] Jillian Seniuk Cicek. Determining the relative importance of the $\mathrm{CEAB}$ graduate attributes for engineering: an explaratory case study at the University of Manitoba. Ph.D. thesis, University of Manitoba, xix-368 pp., 2018. Available as of April 26, 2019 from https://mspace.lib.umanitoba.ca/handle/1993/33076

[10] Monique Sullivan and Robert Brennan, "Graduate attribute assessment practice in Canadian Engineering programs (2010-2017)," Proc. CEEA Canadian Engineering Education Conf., (Vancouver, BC ; 3-6June 2018), 6 pp., 2018

Available as of April 26, 2019 from https://ojs.library.queensu.ca/index.php/PCEEA/arti cle/view/13060

\section{APPENDIX A: LIST OF GRADUATE ATTRIBUTES}

GA1. A knowledge base for engineering: Demonstrated competence in university level mathematics, natural sciences, engineering fundamentals, and specialized engineering knowledge appropriate to the program.

GA2. Problem analysis: An ability to use appropriate knowledge and skills to identify, formulate, analyze, and solve complex engineering problems in order to reach substantiated conclusions

GA3. Investigation: An ability to conduct investigations of complex problems by methods that include appropriate experiments, analysis and interpretation of data and synthesis of information in order to reach valid conclusions.

GA4. Design: An ability to design solutions for complex, open-ended engineering problems and to design systems, components or processes that meet specified needs with appropriate attention to health and safety risks, applicable standards, and economic, environmental, cultural and societal considerations.

GA5. Use of engineering tools: An ability to create, select, apply, adapt, and extend appropriate techniques, resources, and modern engineering tools to a range of engineering activities, from simple to complex, with an understanding of the associated limitations.
GA6. Individual and teamwork: An ability to work effectively as a member and leader in teams, preferably in a multi-disciplinary setting.

GA7. Communication skills: An ability to communicate complex engineering concepts within the profession and with society at large. Such ability includes reading, writing, speaking and listening, and the ability to comprehend and write effective reports and design documentation, and to give and effectively respond to clear instructions.

GA8. Professionalism: An understanding of the roles and responsibilities of the professional engineer in society, especially the primary role of protection of the public and the public interest.

GA9. Impact of engineering on society and the environment: An ability to analyze social and environmental aspects of engineering activities. Such ability includes an understanding of the interactions that engineering has with the economic, social, health, safety, legal, and cultural aspects of society, the uncertainties in the prediction of such interactions; and the concepts of sustainable design and development and environmental stewardship.

GA10. Ethics and equity: An ability to apply professional ethics, accountability, and equity.

GA11. Economics and project management: An ability to appropriately incorporate economics and business practices including project, risk, and change management into the practice of engineering and to understand their limitations.

GA12. Life-long learning: An ability to identify and to address their own educational needs in a changing world in ways sufficient to maintain their competence and to allow them to contribute to the advancement of knowledge.

\section{APPENDIX B: LEXICON OF SYNONYMS}

GA2. Problem analysis: calculation (calculate)

GA3. Investigation: improvement (improve), optimisation (optimise), research, simulation (simulate), testing (test)

GA4. Design: creation (creativity, creative, create), development (develop, developer), imagination (imagine)

GA7. Communication skills: give instructions, listen

GA10. Ethics and equity: honesty (honest), integrity GA11. Economics and project management: manage a team 